\title{
Assessment of the potential utilization of municipal solid waste from a closed irregular landfill
}

\author{
Liming Rong a , Chengliang Zhang a , Dongsheng Jin ${ }^{\text {b }}$, Ziyun Dai c, * \\ ${ }^{a}$ Environmental Protection Research Institute of Light Industry, Beijing Key Laboratory of Industrial Land Contamination and Remediation, \\ Beijing 100089, China \\ ${ }^{\mathrm{b}}$ Institute of Agricultural Environment and Resources, Shanxi Academy of Agricultural Sciences, Taiyuan 030012, China \\ ${ }^{\mathrm{c}}$ Research Center for Eco-Environmental Science, Chinese Academy of Sciences, Beijing 100085, China
}

\section{A R T I C L E I N F O}

\section{Article history:}

Received 9 July 2015

Received in revised form

9 October 2015

Accepted 12 October 2015

Available online 20 October 2015

\section{Keywords:}

Municipal solid waste

Landfill mining

Heavy metals

Recycling

\begin{abstract}
A B S T R A C T
This study assesses the recycling potential of municipal solid waste from a closed irregular landfill in Beijing. The assessment comprises an analysis protocol, including waste composition, chemical characteristics, and environmental bioassays. The waste samples were screened at $10 \mathrm{~mm}$ and $5 \mathrm{~mm}$, which proved to be effective in reducing the heavy metal content. Chemical analyses of the waste soil showed that the concentrations of nutrients were much higher than the relevant standard. The possible phytotoxicity of the waste soil was explored by conducting germination tests on rice seeds (Oryza sativa L.). The results indicated that the waste soil could have adverse effects on the growth of the plants. The newly developed pot experiment with Poa pratensis Linn. showed that a significant improvement in the compatibility of waste soil with plants was induced by the application of coal cinders. Assessment by the toxicity characteristic leaching procedure showed that heavy metal concentrations in the mixed substrates were all below the allowable US standard. In conclusion, the experimental activities conducted demonstrate that recycling waste soil (size $<5 \mathrm{~mm}$ ) is potentially safe and suitable for remediation activities.
\end{abstract}

(c) 2015 Elsevier Ltd. All rights reserved.

\section{Introduction}

As people's quality of life has improved, the volume of municipal solid waste (MSW) generated has increased concurrently. In China, the amount of MSW has averaged a $10 \%$ annual growth rate for the past decade, exceeding 172.4 million tons in 2013 (NBS, 2013). Landfills have long been widely accepted as a way of managing MSW at minimum cost, especially in developing countries. There are more than 1000 landfills located in Beijing (Zhang et al., 2013). Most were built and developed before the current regulations began in 2000 and lack modern environmental technologies for proper leachate and gas management (referred to as irregular landfills). Although more advanced systems are now available to treat MSW, more than 20\% of the MSW generated in Beijing was still disposed of in these irregular landfills in 2013 (BMBS, 2013). The components of MSW stored in irregular landfills are complicated and variable because of the absence of garbage classification (Duan

\footnotetext{
* Corresponding author. Tel.: +86 10 62849189; fax: +86 1082428491

E-mail address: daiziyun1985@163.com (Z. Dai)
}

et al., 2014). In developed countries without significant recycling activity, MSW predominantly includes food wastes, market wastes, yard wastes, plastic containers and product packaging materials, and other miscellaneous solid wastes from residential, commercial, institutional, and industrial sources (US EPA, 1997). The new open sanitary landfills only accept specific waste after strict sorting procedures.

The environmental impacts of the many existing landfills throughout the world cannot be ignored. Methane, generated by the degradation of organic wastes, is a greenhouse gas, and, because of its flammability, can be a danger to local inhabitants (Mou et al., 2014). Many studies have proved that landfill leachate is a significant source of pollutants as a consequence of the leaching of hazardous substances (Melnyk et al., 2014; Li et al., 2012). Landfill leachates are complex; heavy metal components are undoubtedly the most harmful because of their persistence and toxicity (Aronsson et al., 2010). The sprouting of seeds, seedling growth, crop yield, and heavy metals contents of plants are influenced by contaminated soil (Masi et al., 2014; Prabpai et al., 2009). Control of heavy metals in leachates has therefore become a focus of landfill management. Most heavy metals in 
sanitary landfills, which have anti-seepage protection measures, are retained in the waste in a complex form (Prechthai et al., 2008); however, the leachate from irregular landfills connects directly to the groundwater and pollutes the local soil as well. In addition, the oxygen diffusion rate in an irregular landfill is high and efficient owing to the lack of covering layers, which also influences the leaching of heavy metals from the landfill into the environment (Xie et al., 2009).

Environmental treatment of irregular landfills is one of the most difficult issues faced by environmental engineers. Developed countries now frequently transfer aged MSW to sanitary landfills and remediate the polluted land (Hogland et al., 2004). To preserve the volume in new landfills, it is necessary to set up an objective investigation to develop a reclamation plan with site-specific characteristics. The technical process of reclamation generally includes excavation, screening or soil separation, and processing of recyclable or disposable material (Frandegard et al., 2013). Considerable economic benefits can be obtained by the landfill operators from reclaimed materials. Abundant materials, such as plastic and metals, can be recycled directly, and viable energy generation by refuse-derived fuel (RDF) production has also been developed (Bosmans et al., 2013). Landfilling remains the option for non-recyclable waste, of which soil generally constitutes some $75 \%$ of the mass (US EPA, 1997). An interesting remediation technology for these soils is landfill mining to obtain fertilizers for orchards (Krook et al., 2012). High levels of heavy metals in these soils, however, are extremely toxic to plants, which limits their direct application (Farrell and Jones, 2009). Ex situ washing with physical-chemical methods has been used to treat polluted soils of limited size that have been affected by high contamination (Dermont et al., 2008). However, because of high costs and the potential problem of secondary pollution because of application to large areas with low concentrations of contaminants, these methodologies are generally considered to be of limited use. Therefore, before the implementation of a specific landfill mining, an environmental and economic assessment should be taken (Danthurebandara et al., 2015a,b). Based on the assessment results, the local government can attract more social capital to engage in landfill mining (Van Passel et al., 2013).

The local government of Beijing has explicitly proposed carrying out remediation and management of irregular landfills. Driven by this policy, the irregular landfills in Beijing are being closed in a stepwise manner. Although there has been much research conducted in China to characterize the components of MSW (Wang and Wang, 2013) and the environmental risks of leachate (Han et al., 2014) and resource reclamation (Cheng and $\mathrm{Hu}, 2010$ ), as well as to evaluate effects of treatment processes (Zhang et al., 2013), studies to date have not comprehensively determined the potential of recycling waste soil from irregular landfills. The environmental benefits and risks of reusing waste soil are not fully understood. The objectives of this study were therefore (1) to assess the toxicity of waste soil from an irregular landfill in Beijing in terms of heavy metals content, and (2) to analyze the suitability of this waste soil in environmental remediation activities. In this context, composition of the excavated waste from an irregular landfill in Beijing was determined. The toxicity of heavy metals in the waste soil screened from the samples was assessed by determining their concentration. The nutrients of the waste soil to be used for planting were also considered in this study. Moreover, seed germination test was applied on rice seeds (Oryza sativa L.) to evaluate the acute toxicity of heavy metals in the waste soil. A pot experiment was used to evaluate the potential for recycling of the waste soil on Poa pratensis Linn. by varying the growth substrate. In addition, toxic characteristic leaching procedure (TCLP) for the leaching test was conducted by comparing the leaching rate of heavy metals with the required quality standards of waste to be used for environmental remediation activities.

\section{Materials and methods}

\subsection{Site description and sampling}

The irregular landfill in this study, located at Nanqijia Town, Changping District, Beijing, received waste from the 1980s until about 2010. Its predecessor was a sand pit, which has now become a 1.5 ha smoky mountain area. This landfill has no leachate collection system or soil covering. The leachate flowed directly into a nearby river. Most of the surrounding lands are household plots planted with vegetables for the landowners themselves. The possibility of heavy metal toxicity in the leachate therefore has potential health risks for the local residents.

As shown in Fig. 1, the MSW samples were collected in October 2013 by a hydraulic excavator at 1.5-2-m depths from seven sampling locations. The composite sample comprising all seven subsamples weighed approximately $2200 \mathrm{~kg}$. A $275 \mathrm{~kg}$ laboratory sample was obtained using the quarter sampling method. This sample was then analyzed to characterize its composition and quality.

\subsection{Sample separation}

After air-drying, the sample was screened by sieve at $10 \mathrm{~mm}$ and $5 \mathrm{~mm}$. The over-size fractions were manually separated into the following categories as carefully as possible: cloth, stone, paper, metal, plastic, and glass. The specific proportions of each category were characterized by their wet weights.

\subsection{Laboratory analysis}

The sampled materials from the $10 \mathrm{~mm}$ and $5 \mathrm{~mm}$ sieves were subjected to chemical analysis. Heavy metals, including $\mathrm{As}, \mathrm{Cd}, \mathrm{Cr}$, $\mathrm{Cu}, \mathrm{Hg}, \mathrm{Ni}, \mathrm{Pb}$, and $\mathrm{Zn}$, were determined according to standard method GB 15618-1995 published by SEPAC (1995). Total concentrations of all metals (except for mercury) were determined by digestion using a mixture of $\mathrm{HNO}_{3}-\mathrm{HCl}(1 / 3, v / v)$ in a closed highpressure microwave system (Mars 5, CEM, USA). Arsenic was analyzed using a graphite furnace atomic absorption spectrophotometer (5100, PerkinElmer Inc., USA). The concentrations of other heavy metals were measured by inductively coupled plasma optical emission spectroscopy (Optima 2100DV, PerkinElmer Inc.).

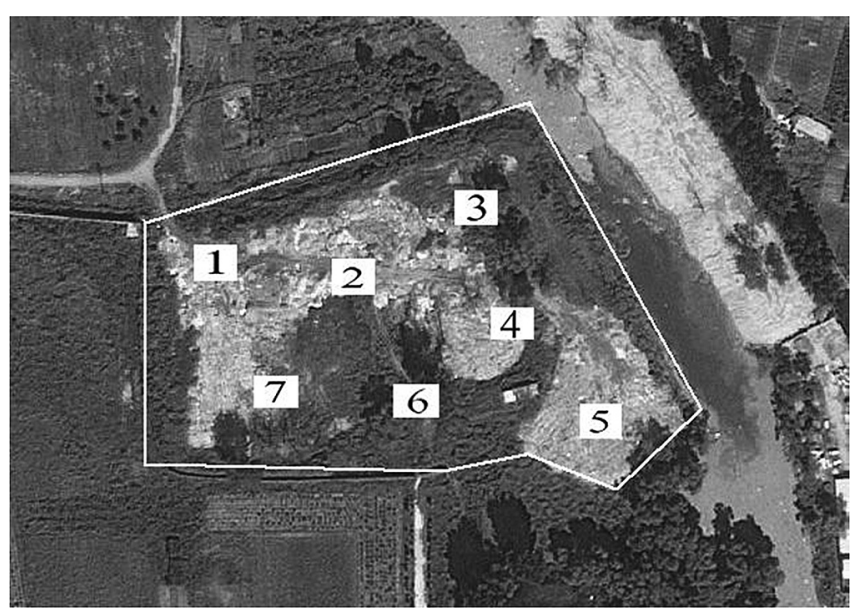

Fig. 1. Sampling locations in the study area. 
Mercury was measured by cold-vapor atomic absorption spectrophotometry (Hydra II C, Leeman Labs, USA).

Based on the standard methods for soil analysis for landscaping use (DB11/T 864-2012; BMBLF, 2012), the pH of the samples was determined using $1 / 10(\mathrm{w} / \mathrm{v})$ soil/distilled water. Bulk density and air porosity were determined using the ring sampler method (Grable and Siemer, 1967). Organic carbon content was determined by the potassium dichromate wet-combustion method (Kalembasa and Jenkinson, 1973). Available nitrogen was determined using a micro-diffusion technique after alkaline hydrolysis (Fu et al., 2000). Available phosphorus was extracted using $0.5 \mathrm{M} \mathrm{NaHCO}_{3}$ and measured spectrometrically (Fu et al., 2000). Available potassium was measured by flame photometry after $\mathrm{NH}_{4} \mathrm{OAc}$ neutral extraction (Qian et al., 1994). Total soluble salt was determined using the Beckman method (Carter et al., 1970).

\subsection{Seed germination toxicity tests}

The sample (size $<5 \mathrm{~mm}$ ) was left in contact with distilled water at a $1 / 10(\mathrm{w} / \mathrm{v})$ ratio and agitated continuously for $15 \mathrm{~h}$ (Walter et al., 2006). The aqueous extract obtained was centrifuged and filtered through ashless filter paper.

The 0 . sativa L. germination test evaluates the phytotoxicity of the soil by comparing a control group grown in distilled water with two experimental groups grown in aqueous extracts at concentrations of $50 \%$ and $75 \%$, respectively. Each repetition comprised the germination of 50 seeds placed on tissue paper in a Petri dish containing $10 \mathrm{ml}$ extracted sample. Fifteen repetitions were carried out in total (five for each group). After an incubation period of $96 \mathrm{~h}$ at $25 \pm 1{ }^{\circ} \mathrm{C}$, the bioassay assessed the germination and root growth of the seeds of rice. The germination index $\left(I_{\mathrm{g}}\right)$ was calculated using the following equation:

$I_{\mathrm{g}}=\frac{G_{\mathrm{C}} * L_{\mathrm{c}}}{G_{\mathrm{t}} * L_{\mathrm{t}}} \times 100 \%$

where $G_{\mathrm{c}}$ is the number of seeds germinated in the sample; $G_{\mathrm{t}}$ is the number of seeds germinated in the control; $L_{\mathrm{c}}$ is the average root length in the sample; and $L_{\mathrm{t}}$ is the average root length in the control.

\subsection{Pot experiments}

Pot experiments were carried out in a greenhouse ( $16 \mathrm{~h}$ of light, $8 \mathrm{~h}$ of dark, $25^{\circ} \mathrm{C}$ during the day, $16^{\circ} \mathrm{C}$ at night). The pot used in this experiment (35 cm in diameter and $30 \mathrm{~cm}$ in height) was plastic and filled with $5 \mathrm{~kg}$ soil. The soil was mixed in five increasing doses of $0 \%, 25 \%, 50 \%, 75 \%$, and $100 \%(\mathrm{~m} / \mathrm{m})$ with inert sample soil (size $<5 \mathrm{~mm}$ ) and with coal cinders (obtained from a coal-fired power station and sieved to pass $5 \mathrm{~mm}$ ).

Five replicates were set up for each of the five soil dosages. Six grams of P. pratensis Linn. seeds were sown in each pot. All pots were irrigated to prevent wilting during the experimental period. To assess the growth status of Kentucky bluegrass, the height and width of the leaves were measured every 20 days. After 100 days, the dry weight of the aboveground part of the plants and the lengths of the taproots were also measured. The growth radical inhibition index $\left(I_{\mathrm{n}}\right)$ was calculated according to the following equation:

$I_{\mathrm{n}}=\frac{L_{\mathrm{c}}-L_{i}}{L_{\mathrm{C}}} \times 100$

where $L_{\mathrm{c}}$ is the root length in the control and $L_{i}$ is the root length in the sample.

\subsection{Leaching potential test}

To determine leaching potential of heavy metals from the mixed substrates used in the pot experiments, an acetic acid leaching test was performed according to method 1311 (US EPA, 2013). The samples were extracted with acetic acid $(\mathrm{pH} 4.9)$ at a $1 / 20(\mathrm{w} / \mathrm{v})$ ratio and then agitated continuously at $30 \mathrm{rpm}$ for $18 \mathrm{~h}$. The aqueous extract obtained was filtered through a membrane filter and the heavy metals concentration analyzed. The measurements of heavy metals (including $\mathrm{As}, \mathrm{Cd}, \mathrm{Cr}, \mathrm{Cu}, \mathrm{Ni}, \mathrm{Pb}$, and $\mathrm{Zn}$ ) in the extracted leachate were based on the standard methods for water and wastewater analysis described in $\mathrm{HJ}$ 700-2014 published by MEPC (2014), and then determined by inductively coupled plasma optical emission spectroscopy (Optima 2100DV, PerkinElmer Inc.).

\section{Results and discussion}

\subsection{Sample compositions}

Fig. 2 presents the compositions of MSW (by weight) in the samples based on size. The results show that the excavated waste comprised $48.6 \%$ oversize material when subjected to screening at $10 \mathrm{~mm}$. The major identifiable components of the waste were plastics, stone, and glass, comprising $13.9 \%, 13.2 \%$, and $8.2 \%(\mathrm{w} / \mathrm{w})$, respectively. Unlike organic waste, which is reduced in the forms of leachate and gas, these non-biodegradable components accumulate over the years (Jain et al., 2005). Subsequent screening at $5 \mathrm{~mm}$ gave $29.9 \%$ over-size material. The waste fraction components were similar to those of the $10 \mathrm{~mm}$ screening. There was little variation in waste composition in the different size fractions, which was
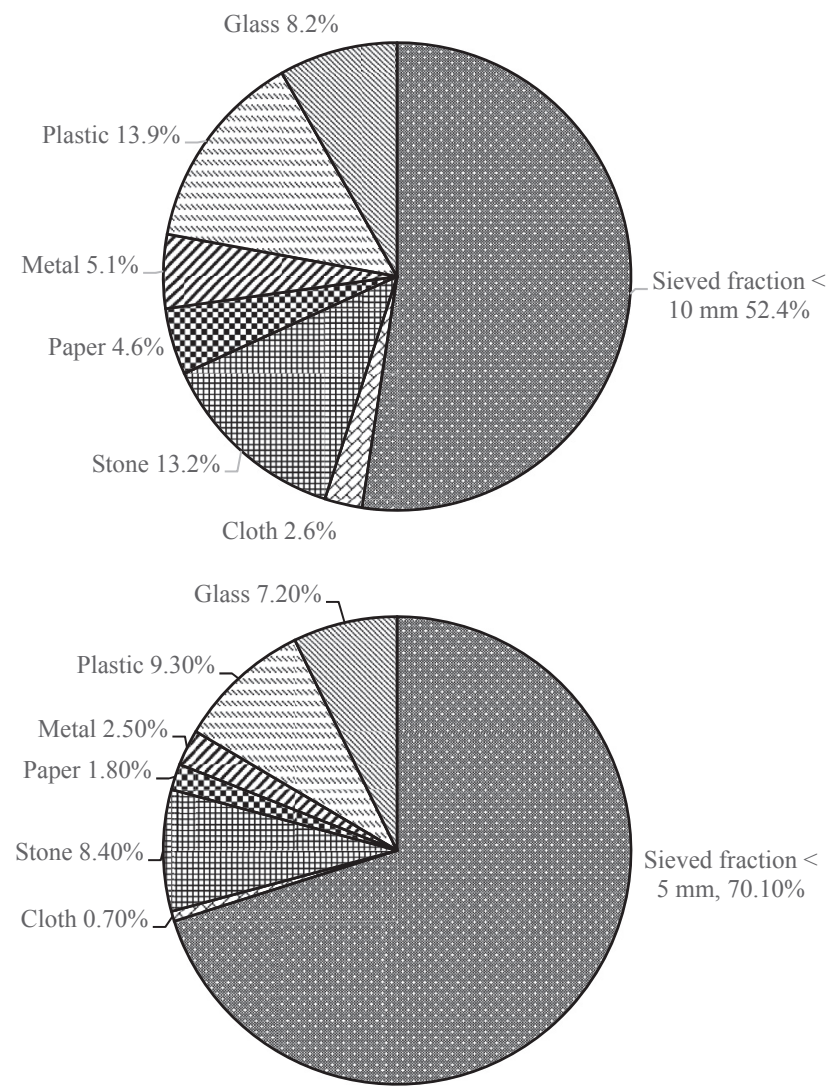

Fig. 2. The composition of MSW (\%,w/w) in the samples sieved at $10 \mathrm{~mm}$ (top graph) and $5 \mathrm{~mm}$ (below graph). 
because of the sampling location in the landfill. Most of the waste with a particle size below $5 \mathrm{~mm}$ was composed of soil. This result can be compared with those of Quaghebeur et al. (2013), who found the soil percentage to vary between $40 \%$ and $70 \%$, depending on the heterogeneity of waste in decomposing. The composition of this landfill, with an average $70.1 \%$ of fine particles, suggests that waste soil is a key factor in irregular landfill remediation and resource recovery.

\subsection{Chemical characteristics of waste soil}

The concentrations of heavy metals in the waste soil in the different size fractions are shown in Table 1. The results show that the concentrations of heavy metals contained in the $<10 \mathrm{~mm}$ waste were much higher than those in the $<5 \mathrm{~mm}$ material, in agreement with the work of Quaghebeur et al. (2013) who reported that most of the heavy metals in the waste soil can be removed by sieving. To determine the acceptable concentration limits of these heavy metals, we referred to the environmental quality standard for soils set by SEPAC for the normal growth of plants (SEPAC, 1995). Concentrations of $\mathrm{As}, \mathrm{Cu}, \mathrm{Cr}$, and $\mathrm{Pb}$ in both size fractions $(<5 \mathrm{~mm}$ and $<10 \mathrm{~mm}$ ) met these regulatory limits (Table 1 ). The concentrations of $\mathrm{Zn}, \mathrm{Cd}, \mathrm{Ni}$, and $\mathrm{Hg}$ in all waste samples were higher than these limits. The highest $\mathrm{Zn}$ concentration was found in the waste size $<10 \mathrm{~mm}$. Zn and particularly Cd concentrations in both waste sizes most exceeded the limits. Kitchen waste, ash, plastic, and paper are considered important sources of Zn in MSW (Long et al., 2011). The high concentration of $\mathrm{Cd}$ in the waste soil is probably sourced from the plastic softeners, stabilizers, and pigments (Rotter et al., 2004). In addition, batteries are an important source of heavy metals in MSW (Xara et al., 2013), which is confirmed by the presence of high concentrations of $\mathrm{Hg}$ and $\mathrm{Ni}$ in both waste sizes.

To evaluate the possibility of recycling the $<5 \mathrm{~mm}$ waste as planting soil, we determined its physical and chemical properties and compared these with the soil requirements for landscaping use (Table 2). The $\mathrm{pH}$, bulk density, air porosity, organic carbon content, and available $\mathrm{N}, \mathrm{P}$, and $\mathrm{K}$ of this sample were within the acceptable limits, except for total soluble salt, which was much higher than the required compost quality standards. Other studies have shown that the high soluble salt content in waste soil is not conducive to the growth of plant roots (Michitsch et al., 2007). Despite the high salt content, the high organic carbon content and available $\mathrm{N}, \mathrm{P}$, and $\mathrm{K}$ in this waste soil indicate that it could be suitable for providing plant nutrients required for growth.

\subsection{Germination tests with rice seed}

Fig. 3 shows the results of the rice germination tests inhibited by the toxicity of waste in the size fraction $<5 \mathrm{~mm}$. The average GI

\section{Table 1}

Heavy metal concentrations of the samples sieved at $10 \mathrm{~mm}$ and $5 \mathrm{~mm}$ compared with the environmental quality standard for soils set by SEPAC $(\mathrm{mg} / \mathrm{kg})$.

\begin{tabular}{lccc}
\hline $\begin{array}{l}\text { Heavy } \\
\text { metal }\end{array}$ & Waste size $<10 \mathrm{~mm}$ & Waste size $<5 \mathrm{~mm}$ & $\begin{array}{l}\text { Regulatory } \\
\text { limits }^{\mathrm{a}}\end{array}$ \\
\hline $\mathrm{As}$ & $18.6 \pm 4.3$ & $11.3 \pm 2.6$ & 40 \\
$\mathrm{Cu}$ & $112.3 \pm 15.8$ & $76.4 \pm 6.4$ & 400 \\
$\mathrm{Zn}$ & $15,100 \pm 3400$ & $6200 \pm 1200$ & 500 \\
$\mathrm{Cd}$ & $151.6 \pm 24.7$ & $102.8 \pm 13.9$ & 1 \\
$\mathrm{Cr}$ & $92.8 \pm 10.2$ & $72.6 \pm 8.9$ & 300 \\
$\mathrm{~Pb}$ & $94.8 \pm 9.4$ & $66.7 \pm 5.1$ & 500 \\
$\mathrm{Ni}$ & $346.7 \pm 44.8$ & $274.2 \pm 27.3$ & 200 \\
$\mathrm{Hg}$ & $4.6 \pm 0.4$ & $3.1 \pm 0.2$ & 1.5 \\
\hline
\end{tabular}

${ }^{a}$ Regulatory limits are concentration limits of heavy metals in soils for the normal growth of plants.
Table 2

Properties of the samples size $<5 \mathrm{~mm}$ compared with the soil requirements for landscaping use set by BMBLF.

\begin{tabular}{lcl}
\hline Property & Waste size $<5 \mathrm{~mm}$ & $\begin{array}{l}\text { Compost quality } \\
\text { standard }^{\text {a }}\end{array}$ \\
\hline $\mathrm{pH}$ & $8.0 \pm 0.5$ & $6.5-8.5$ \\
Total soluble salt $(\%)$ & $0.7 \pm 0.1$ & $\leq 0.12$ \\
Bulk density $\left(\mathrm{g} / \mathrm{m}^{3}\right)$ & $1.01 \pm 0.13$ & $\leq 1.35$ \\
Air porosity $(\%)$ & $3.4 \pm 2.1$ & $5-8$ \\
Organic carbon content $(\mathrm{g} / \mathrm{kg})$ & $55.7 \pm 10.7$ & $\geq 10$ \\
Available N $(\mathrm{mg} / \mathrm{kg})$ & $241.9 \pm 38.2$ & $\geq 60$ \\
Available $\mathrm{P}(\mathrm{mg} / \mathrm{kg})$ & $75.1 \pm 12.6$ & $\geq 10$ \\
Available $\mathrm{K}(\mathrm{mg} / \mathrm{kg})$ & $480.4 \pm 37.4$ & $\geq 100$ \\
\hline
\end{tabular}

${ }^{\text {a }}$ Compost quality standard is suitable for turf and trees growth in soils.

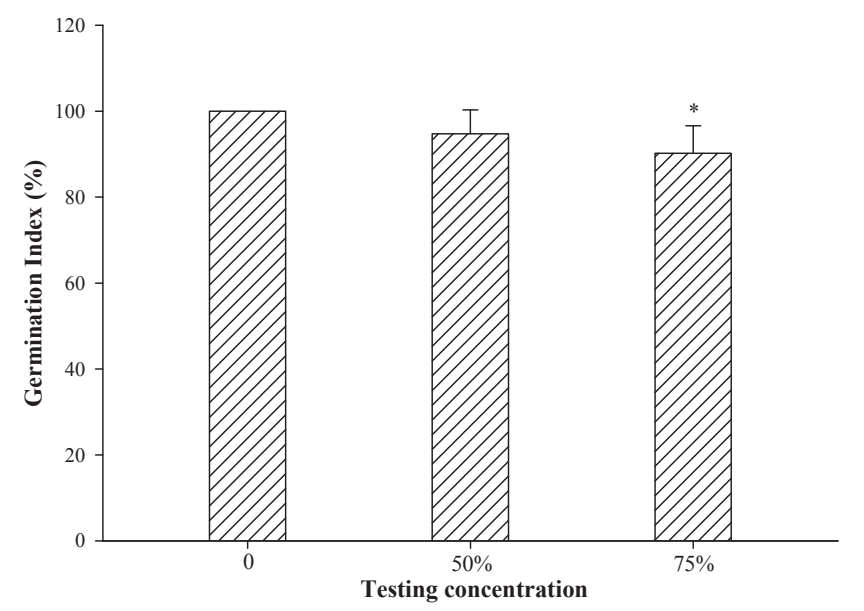

Fig. 3. Germination index of Oryza sativa L. inhibited by the toxicity of waste soil.

values were about $94 \%$ and $90 \%$ for the tests containing $50 \%$ and $75 \%$, respectively, of the landfill soil. Both of these compositions were above the minimum limit for GI in the standard compost (IEPA, 2003). The results indicate that the soil from this landfill is less toxic to this species, and it is feasible to use this soil as a plant growth substrate. Fig. 3 also shows that the germination index decreased as the concentration of landfill soil in the growth medium increased. There were no significant statistical differences between the control and 50\% groups, but the $75 \%$ group was statistically differentiated at a level of significance of $p=0.05$. This confirmed that this waste can induce an adverse effect and that the toxic effect on plant growth can be reduced by dilution.

\subsection{Recycling suitability test}

The test with Kentucky bluegrass was carried out to evaluate the suitability of waste soil recycling for landscape use. This species was selected because it has a fine leaf surface and is commonly used in landscaping. Moreover, this species has a certain tolerance to heavy metal stress and is suitable for planting in soils that are heavily polluted by heavy metals (Liu et al., 2006). The judgment of suitability is based primarily on the status of plant growth, such as plant height (Fig. 4a), leaf width (Fig. 4b), the average dry weight of the aboveground biomass (Fig. 5), and the growth radical inhibition index (Fig. 6).

Observing the trends of plant height and leaf width of Kentucky bluegrass (Fig. 4), we found that the application of coal cinders significantly improved the compatibility of waste soil with plants. The cinders were added to increase water retention and aeration properties and avoid soil compaction. Because of their porosity, 

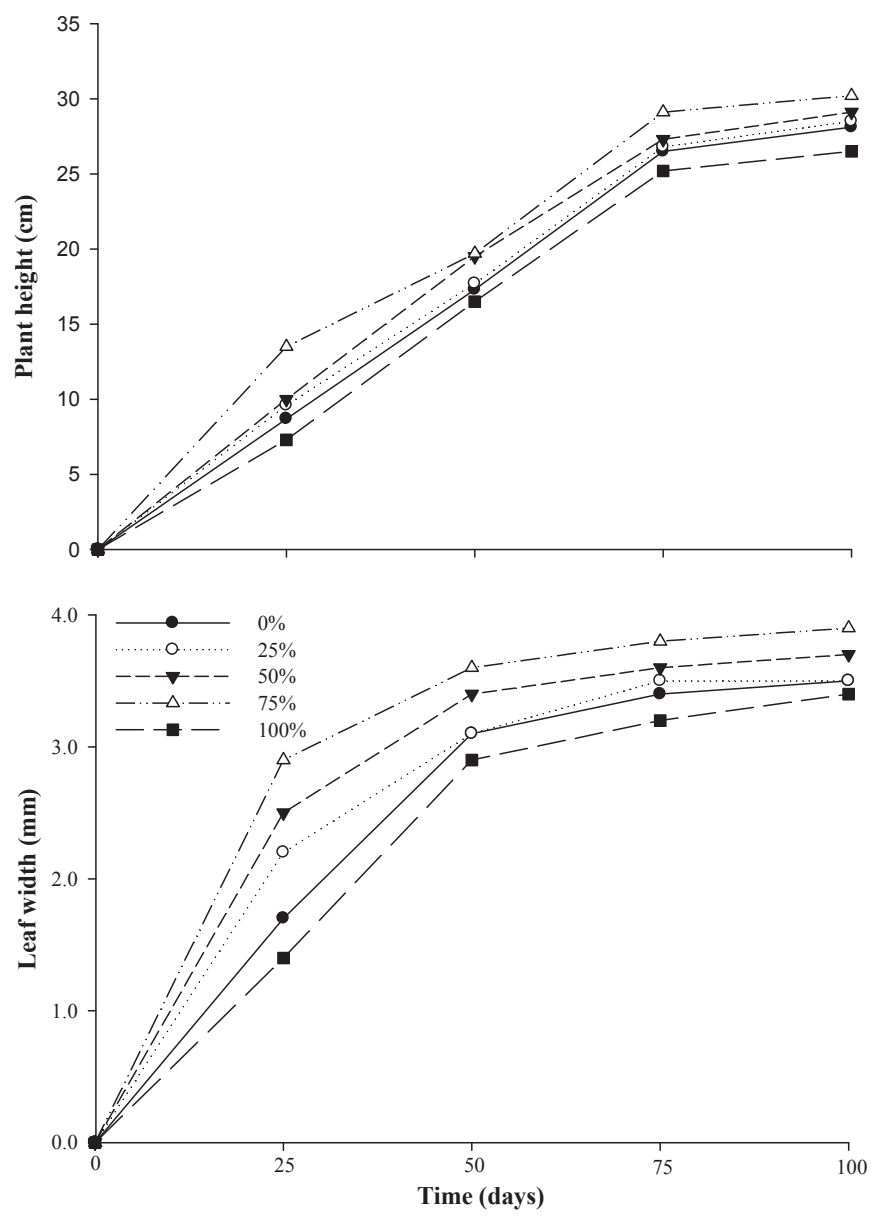

Fig. 4. Results of plant height and leaf width of Poa pratensis Linn. in the pot experiments.

cinders can also reduce the activity of heavy metal ions in soil by adsorption (Lian et al., 2013). Because of the absence of nutritional elements, pure coal cinders are not conducive to the growth of plants. The substrate comprising $100 \%$ coal cinders therefore gave the worst results. Plant growth improved with increasing cinder content in the mixed substrate. At the beginning of the

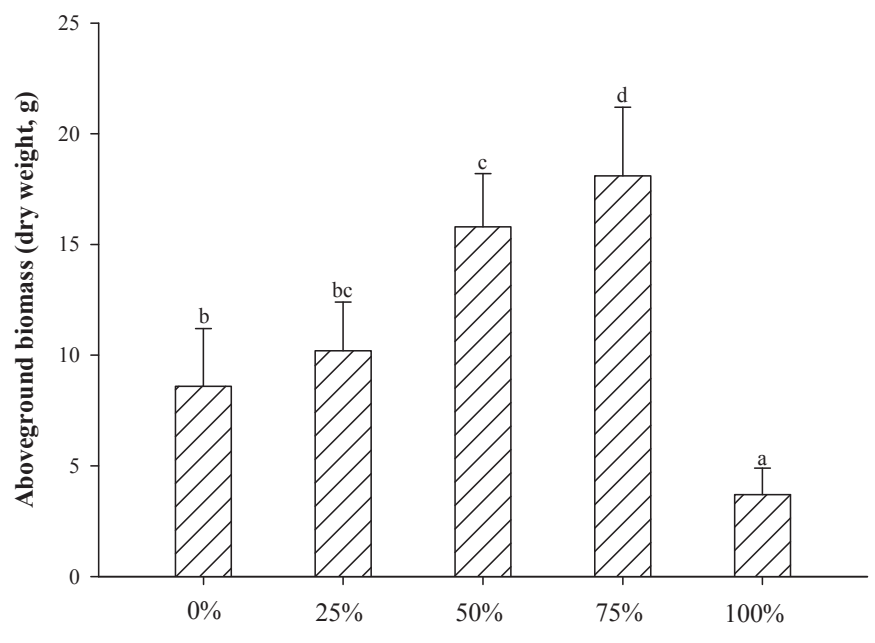

Fig. 5. The results of the aboveground biomass of Poa pratensis Linn. in the pot experiments.

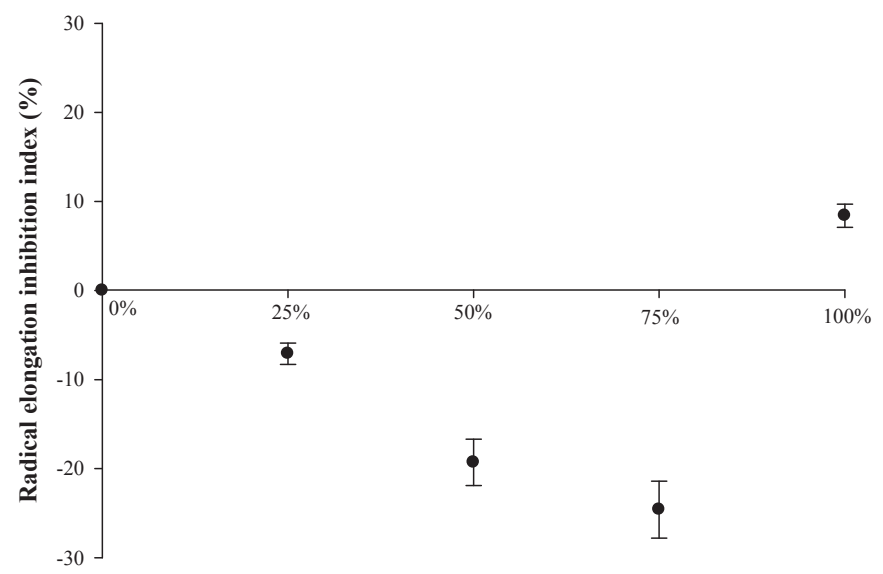

Fig. 6. The results of growth radical inhibition index Poa pratensis Linn. in the pot experiments.

experiments, the differences in plant height and leaf width caused by the different media were very obvious. With the passage of time, however, these differences gradually narrowed. This result agrees with that of Siddiqui et al. (2014), who found that the toxicity of waste soil more obviously affects plants during the germination period. In the pot experiments, the best mixing ratio was found when using $75 \%$ cinders.

Aboveground biomass data for Kentucky bluegrass grown under all conditions are shown in Fig. 5. The biomass distribution showed great variance. Specifically, compared with the control, cinder content significantly $(p<0.05)$ inhibited the biomass accumulation. Similar to the trends for plant height and leaf width, the media containing $75 \%$ cinders showed the highest biomass accumulation (18.1 g) -almost five times higher than that of pure cinders (3.7 g). The radical elongation inhibition index showed large variations for the different treatments, ranging from $-24.6 \%$ (75\% group) to $8.4 \%$ (100\% group) (Fig. 6). A similar trend was observed for the different treatments. In addition, the inhibition index data indicate that waste soil treated with cinders has a positive impact on the root growth of plants.

\subsection{Leaching potential of mixed substrates}

The leaching potentials of the mixed substrates are reported in Fig. 7. Among all detected heavy metals, the concentration of $\mathrm{Zn}$ was highest in the mixed substrate whereas $\mathrm{Cu}$ concentration was

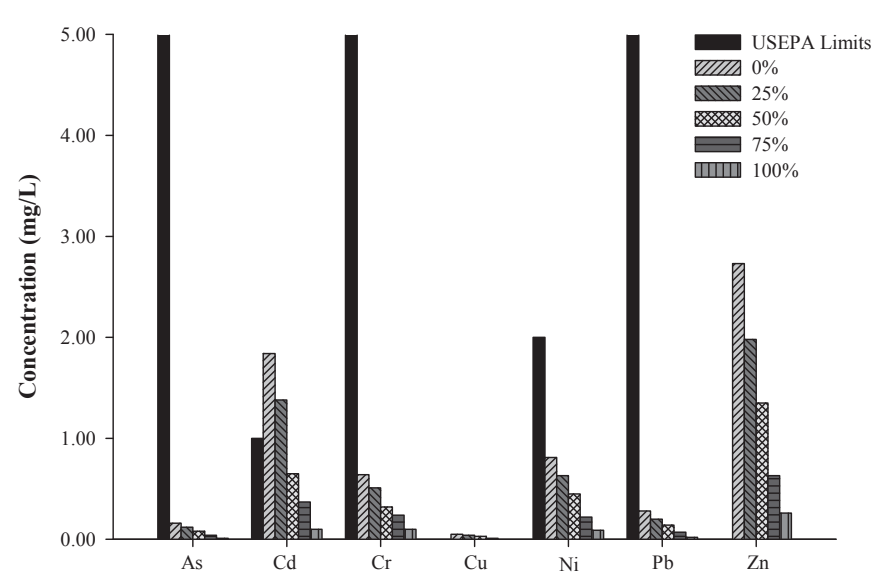

Fig. 7. The leaching potential of mixed substrates. 
the lowest. It is interesting to observe that, although the concentration of $\mathrm{Cd}$ in the samples was lower than that of $\mathrm{Ni}$, its leaching potential was clearly higher. The concentrations of the analyzed metals were found to be lower than the allowable heavy metal concentrations under the US toxicity characteristic leaching procedure (TCLP) standard (US EPA, 2013), except for Cd in the $0 \%$ and $25 \%$ groups. The leachate of the mixed substrate will therefore need to be continuously monitored, especially for $\mathrm{Cd}$, to avoid environmental risks of this remediation practice.

\section{Conclusions}

In an urban setting, irregular landfills occupy valuable land resources and cause adverse environmental impacts. This study assessed the toxicity of waste soil originating from an irregular landfill in Beijing and analyzed the suitability of waste soil for environmental remediation activities. The irregular landfill is heterogeneous in nature with varying composition, constituted mainly of a very fine fraction ( $<5 \mathrm{~mm}$ ). Using $10-\mathrm{mm}$ and 5 -mm sieves for physical separation, a high percentage of plastic, stone, and glass can be effectively removed.

Chemical analyses showed 30\% lower heavy metal concentration in the fine fraction $(<5 \mathrm{~mm})$ compared with the $<10 \mathrm{~mm}$ fraction. Screening is therefore an effective way of separating the fraction that has higher concentrations of heavy metals. However, direct recovery of the $<5 \mathrm{~mm}$ waste as planting soil may be limited because of the high concentrations of heavy metal and total soluble salt content in this material, although the nutrient concentrations are higher than the BMBLF standards for soil used in landscaping.

Seed germination tests on $O$. sativa $\mathrm{L}$. indicated that the biological phytotoxicity of waste soil could have particularly adverse effects on the growth of this species; however, this effect can be reduced by dilution.

The results of long-term pot experiments on P. pratensis Linn. indicated that application of coal cinders significantly improves the compatibility of waste soil with plants. The study species showed the best growth status for waste soil treated with $75 \%$ cinders. Mixed substrates containing this cinder content showed very low heavy metal concentrations in leaching potential test, with all metals below the allowable U.S. TCLP standard. Recycling of this waste soil is therefore possibly safe and suitable for remediation activities.

In the case of an irregular landfill in Beijing, we can conclude that waste soil (size $<5 \mathrm{~mm}$ ) has high potential to be recycled in environmental remediation activities. In full-scale application, a reclamation operation in the landfill needs to first remove stone, glass, metal, and plastic from the waste soil. Further studies will investigate the possible use of waste soil as compost, especially for non-edible crops.

\section{Acknowledgments}

This research project was funded by the Major Science and Technology Project in Shanxi Province-Research and the Demonstration of Environmental Monitoring and Ecological Restoration Technology in Industrial and Mining Areas (No. 20121101009-07).

\section{References}

Aronsson, P., Dahlin, T., Dimitriou, I., 2010. Treatment of landfill leachate by irrigation of willow coppice - plant response and treatment efficiency. Environ. Pollut. 158, 795-804.

BMBLF, 2012. Soil Requirements for Landscaping Use (DB11/T 864-2012). Beijing Municipal Bureau of Landscape and Forestry, Beijing.

BMBS, 2013. 2014 Beijing Statistical Yearbook. Beijing Municipal Bureau of Statistics, Beijing.
Bosmans, A., Vanderreydt, I., Geysen, D., et al., 2013. The crucial role of waste-toenergy technologies in enhanced landfill mining: a technology review. J. Clean. Prod. 55, 10-23.

Carter, D.L., Bondurant, J.A., Robbins, C.W., 1970. Water-soluble $\mathrm{NO}_{3}$-nitrogen, $\mathrm{PO}_{4}$ phosphorus, and total salt balances on a large irrigation tract. Soil Sci. Soc. Am. J. 35, 331-335.

Cheng, H.F., Hu, Y.N., 2010. Municipal solid waste (MSW) as a renewable source of energy: current and future practices in China. Bioresour. Technol. 101, $3816-3824$.

Danthurebandara, M., Van Passel, S., Machiels, L., Van Acker, K., 2015a. Valorization of thermal treatment residues in enhanced landfill mining: environmental and economic evaluation. J. Clean. Prod. 99, 275-285.

Danthurebandara, M., Van Passel, S., Van Acker, K., 2015b. Environmental and economic assessment of 'open waste dump' mining in Sri Lanka. Resour. Conserv. Recycl. 102, 67-79.

Dermont, G., Bergeron, M., Mercier, G., 2008. Soil washing for metal removal: a review of physical/chemical technologies and field applications. J. Hazard. Mater. 152, 1-31.

Duan, Z.H., Lu, W.J., Li, D., et al., 2014. Temporal variation of trace compound emission on the surface of a landfill in Beijing, China. Atmos. Environ. 88, 230-238.

Farrell, M., Jones, D.L., 2009. Critical evaluation of municipal solid waste composting and potential compost markets. Bioresour. Technol. 100, 4301-4310.

Frandegard, P., Krook, J., Svensson, N., et al., 2013. A novel approach for environmental evaluation of landfill mining. J. Clean. Prod. 55, 24-34.

Fu, B.J., Chen, L.D., Ma, K.M., et al., 2000. The relationships between land use and soil conditions in the hilly area of the loess plateau in northern Shaanxi, China. Catena 39, 69-78.

Grable, A.R., Siemer, E.G., 1967. Effects of bulk density, aggregate size, and soil water suction on oxygen diffusion, redox potentials, and elongation of corn roots. Soil Sci. Soc. Am. J. 32, 180-186.

Han, D.M., Tong, X.X., Currell, M.J., et al., 2014. Evaluation of the impact of an uncontrolled landfill on surrounding groundwater quality, Zhoukou, China. J. Geochem. Explor. 136, 24-39.

Hogland, W., Marques, M., Nimmermark, S., 2004. Landfill mining and waste characterization: a strategy for remediation of contaminated areas. J. Mater Cycles Waste 6, 119-124.

Italian Environmental Protection Agency (IEPA), 2003. Microbiological Methods of Analysis of Compost. Manuals and Guidelines 20/2003.

Jain, P., Kim, H., Townsend, T.G., 2005. Heavy metal content in soil reclaimed from a municipal solid waste landfill. Waste Manag. 25, 25-35.

Kalembasa, S.J., Jenkinson, D.S., 1973. A comparative study of titrimetric and gravimetric methods for the determination of organic carbon in soil. J. Sci. Food Agric. 24, 1085-1090.

Krook, J., Svensson, N., Eklund, M., 2012. Landfill mining: a critical review of two decades of research. Waste Manag. 32, 513-520.

Li, Y., Li, J.H., Chen, S.S., et al., 2012. Establishing indices for groundwater contamination risk assessment in the vicinity of hazardous waste landfills in China. Environ. Pollut. 165, 77-90.

Lian, J.J., Xu, S.G., Chang, N.B., et al., 2013. Removal of molybdenum (VI) from mine mailing effluents with the aid of loessial soil and slag waste. Environ. Eng. Sci. 30, 213-220.

Liu, Y.G., Zhang, H.Z., Zeng, G.M., et al., 2006. Heavy metal accumulation in plants on Mn mine tailings. Pedosphere 16, 131-136.

Long, Y.Y., Shen, D.S., Wang, H.T., 2011. Heavy metal source analysis in municipal solid waste (MSW): case study on Cu and Zn. J. Hazard. Mater. 186, 1082-1087.

Masi, S., Caniani, D., Grieco, E., et al., 2014. Assessment of the possible reuse of MSW coming from landfill mining of old open dumpsites. Waste Manag. 34, 702-710.

Melnyk, A., Kuklinska, K., Wolska, L., 2014. Chemical pollution and toxicity of water samples from stream receiving leachate from controlled municipal solid waste (MSW) landfill. Environ. Res. 135, 253-261.

MEPC, 2014. Water Quality-Determination of 65 Elements-Inductively Coupled Plasma-Mass Spectrometry (HJ 700-2014). Ministry of Environmental Protection of China, Beijing, China.

Michitsch, R.C., Chong, C., Holbein, B.E., et al., 2007. Use of wastewater and compost extracts as nutrient sources for growing nursery and turfgrass species. J. Environ. Qual. 36, 1031-1041.

Mou, Z.S., Scheutz, C., Kjeldsen, P., 2014. Evaluating the biochemical methane potential (BMP) of low-organic waste at Danish landfills. Waste Manag. 34, 2251-2259.

NBS, 2013. 2014 China Statistical Yearbook. National Bureau of Statistics, Beijing.

Prabpai, S., Charerntanyarak, L., Siri, B., et al., 2009. Effects of residues from municipal solid waste landfill on cornyield and heavy metal content. Waste Manag. 29, 2316-2320.

Prechthai, T., Padmasri, M., Visvanathan, C., 2008. Quality assessment of mined MSW from an open dumpsite from recycling potential. Resour. Conserv. Recycl. 53, 70-78.

Qian, P., Schoenaru, J.J., Karamanos, R.E., 1994. Simultaneous extraction of available phosphorus and potassium with a new soil test: a modification of Kelowna extraction. Commun. Soil Sci. Plan. 25, 5-6.

Quaghebeur, M., Laenen, B., Geysen, D., et al., 2013. Characterization of landfilled materials: screening of the enhanced landfill mining potential. J. Clean. Prod. $55,72-83$.

Rotter, V.S., Kost, T., Winkler, J., et al., 2004. Material flow analysis of RDFproduction process. Waste Manag. 24, 1005-1021. 
SEPAC, 1995. Environmental Quality Standard for Soils (GB 15618-1995). State Environmental Protection Administration of China, Beijing.

Siddiqui, M.M., Abbasi, B.H., Ahmad, N., et al., 2014. Toxic effects of heavy metals $(\mathrm{Cd}, \mathrm{Cr}$ and $\mathrm{Pb})$ on seed germination and growth and DPPH-scavenging activity in Brassica rapa var. turnip. Toxicol. Ind. Health 30, 238-249.

US EPA, 1997. Landfill Reclamation. Office of Solid Waste and Emergency Response (5305W). EPA530-F-97-001, July, Washington, DC.

US EPA, 2013. Test Methods for Evaluating Solid Wastes (SW-846).

Van Passel, S., Dubois, M., Eyckmans, J., de Gheldere, F., Tom, J.P., Van Acker, K., 2013. The economics of enhanced landfill mining: private and societal performance drivers. J. Clean. Prod. 55, 92-102.

Walter, I., Martínez, F., Cala, V., 2006. Heavy metal speciation and phytotoxic effects of three representative sewage sludges for agricultural uses. Environ. Pollut. 139, 507-514.
Wang, H., Wang, C.M., 2013. Municipal solid waste management in Beijing: characteristics and challenges. Waste Manag. Res. 31, 67-72.

Xara, S., Delgado, J., Almeida, M.F., et al., 2013. Laboratory study on the leaching potential of spent alkaline batteries using a MSW landfill leachate. J. Mater. Cycles Waste 15, 61-72.

Xie, H.J., Chen, Y.M., Zhan, L.T., et al., 2009. Investigation of migration of pollutant at the base of Suzhou Qizishan landfill without a liner system. J. Zhejiang Univ. Sci. A $10,439-449$.

Zhang, C.H., Wang, K., Tan, S.H., 2013. Evaluation and remediation of organics, nutrients and heavy metals in landfill leachate - a case study in Beijing. Chem. Ecol. 29, 668-675. 